\title{
Integrating Pathways of Parkinson's Disease in a Molecular Interaction Map
}

\author{
Kazuhiro A. Fujita • Marek Ostaszewski • Yukiko Matsuoka • Samik Ghosh • \\ Enrico Glaab • Christophe Trefois • Isaac Crespo • Thanneer M. Perumal • \\ Wiktor Jurkowski • Paul M. A. Antony • Nico Diederich • Manuel Buttini • \\ Akihiko Kodama • Venkata P. Satagopam • Serge Eifes • Antonio del Sol • \\ Reinhard Schneider $\cdot$ Hiroaki Kitano $\cdot$ Rudi Balling
}

Received: 15 April 2013 / Accepted: 13 June 2013 / Published online: 7 July 2013

(C) The Author(s) 2013. This article is published with open access at Springerlink.com

\begin{abstract}
Parkinson's disease (PD) is a major neurodegenerative chronic disease, most likely caused by a complex interplay of genetic and environmental factors. Information on various aspects of PD pathogenesis is rapidly increasing and needs to be efficiently organized, so that the resulting data is available for exploration and analysis. Here we introduce a computationally tractable, comprehensive molecular interaction map of PD. This map integrates pathways implicated in PD pathogenesis such as synaptic and mitochondrial dysfunction, impaired protein degradation, alpha-synuclein pathobiology and neuroinflammation. We also present bioinformatics tools for the analysis, enrichment and annotation of the map, allowing the research community to open new avenues in PD research. The PD map is accessible at http://minerva.uni.lu/pd_map.
\end{abstract}

K. Fujita and M. Ostaszewski contributed equally to this work.

Electronic supplementary material The online version of this article (doi:10.1007/s12035-013-8489-4) contains supplementary material, which is available to authorized users.

\section{K. A. Fujita $\cdot$ Y. Matsuoka $\cdot$ S. Ghosh $\cdot$ H. Kitano}

The Systems Biology Institute, Minato-ku, Tokyo, Japan

M. Ostaszewski $\cdot$ E. Glaab $\cdot$ C. Trefois $\cdot$ I. Crespo $\cdot$

T. M. Perumal $\cdot$ W. Jurkowski $\cdot$ P. M. A. Antony $\cdot$ N. Diederich $\cdot$

M. Buttini $\cdot$ V. P. Satagopam $\cdot$ S. Eifes $\cdot$ A. del Sol $\cdot$ R. Schneider $\cdot$

R. Balling $(\bowtie)$

Luxembourg Centre for Systems Biomedicine (LCSB),

University of Luxembourg, 7, Avenue des Hauts-Fourneaux,

Esch-sur-Alzette, Luxembourg

e-mail: rudi.balling@uni.lu

M. Ostaszewski

Integrated Biobank of Luxembourg, Luxembourg City,

Luxembourg

N. Diederich

Department of Neuroscience, Centre Hospitalier Luxembourg,

Luxembourg City, Luxembourg
Keywords Parkinson's disease · Molecular neuropathology $\cdot$ Knowledge repository $\cdot$ Bioinformatics

\section{Introduction}

Parkinson's disease (PD) is a major neurodegenerative disease, characterized clinically by a range of symptoms, in particular, impaired motor behaviour. The pathogenesis of $\mathrm{PD}$ is multi-factorial and age-related, implicating various genetic and environmental factors [1]. Gaps in the understanding of the underlying molecular mechanisms hamper the design of effective disease modifying therapies. Investigation of such a complex disease requires a proper knowledge repository that

\author{
A. Kodama \\ Faculty of Medicine, Tokyo Medical and Dental University, Tokyo, \\ Japan \\ V. P. Satagopam $\cdot$ R. Schneider \\ Computational Biology Unit, European Molecular Biology \\ Laboratory, Heidelberg, Germany \\ H. Kitano \\ Sony Computer Science Laboratories, Shinagawa-ku, Tokyo, \\ Japan \\ H. Kitano \\ Division of Systems Biology, Cancer Institute, Tokyo, Japan \\ H. Kitano \\ Open Biology Unit, Okinawa Institute of Science and Technology, \\ Kunigami, Okinawa, Japan
}


organizes the rapidly growing PD-related knowledge - a disease map.

The concept of a disease map is relatively new and has found only a limited application in the field of neurodegenerative diseases thus far $[2,3]$. Such a map represents diagrammatically interactions between molecular components and pathways reported to play a role in disease pathogenesis and progression. It provides navigation and exploration tools that help the user to locate specific areas of interest and visualize known interactions. Associated analytical tools allow investigators to develop a profound understanding of the disease, detect unexpected interactions and ultimately identify new research hypotheses.

In this paper, we present a PD molecular interaction map that captures and visualizes all major molecular pathways involved in PD pathogenesis. Furthermore, it constitutes a resource for computational analyses and a platform for community level collaborations $[4,5]$ (see Fig. 1). We also present how a set of bioinformatics tools applied to the map can facilitate in-depth knowledge extraction and continuous curation.

The paper is divided into two parts. In the first part, we review the pathways implicated in PD, with a focus on synaptic and mitochondrial dysfunction, $\alpha$-synuclein pathobiology, failure of protein degradation systems, neuroinflammation and apoptosis. In the second part of the paper, we demonstrate how the PD map interfaces with bioinformatics tools and databases for its content annotation, enrichment with experimental results, and analysis of its complex structure and dynamics. The PD map is accessible under http://minerva.uni.lu/pd_map (Online resource 1), as a SBML file (Online resource 2), and Payao, a community platform for pathway model curation [264].

\section{Neurodegeneration in Parkinson's Disease Arises from Dysregulation of Interlinked Molecular Pathways}

The major pathological feature of PD is the progressive degeneration of the nigrostriatal system, leading to the loss of dopaminergic (DA) neurons in the substantia nigra pars compacta (SNpc) [6]. The degeneration of the nigrostriatal pathway and subsequent loss of striatal dopamine contributes to the cardinal clinical motor symptoms: tremor, rigidity, bradykinesia and postural instability [7]. Although treatments such as dopamine substitution and deep brain stimulation alleviate many of the motor symptoms, there is no disease-modifying therapy preventing the progressive loss of DA neurons [8].

Susceptibility for PD is modulated by various environmental factors [9-13], genetic predisposition or risk factors [14] and epigenetic alterations $[15,16] .{ }^{1}$ Exposure to pesticides and industrial agents has been associated with an increased

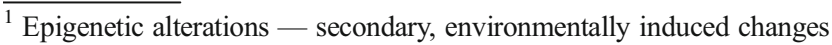
of gene expression.
}

risk for $\mathrm{PD}[17,18]$, but to date none of these agents have been consistently identified as a causal factor for PD [19]. It is known that exposure to inhibitors of mitochondrial respiration [20-25] are sufficient to induce PD symptoms in humans and DA neurodegeneration in animal models.

In this paper, we focus on DA neurons as a major point of convergence in PD disease pathways. However, pathogenic pathways leading to the demise of DA neurons may impact any neuronal population affected in $\mathrm{PD}$, including those of the autonomic ganglia [26, 27]. The demise of these populations may contribute to a range of PD-typical non-motor symptoms hampering the life of PD patients, such as constipation and dysautonomia (ganglia of autonomous nervous system), cognitive decline and REM sleep behaviour (cholinergic neurons of the nucleus basalis of Meynert, noradrenergic coeruleussubcoeruleus complex), depression and apathy (serotinergic caudal raphe nuclei, cholinergic gigantocellular reticular nucleus) $[28,29]$.

\section{Vulnerability and Preferential Loss of Midbrain Dopaminergic Neurons}

SNpc DA neurons are the most vulnerable population of neurons in PD. It has been suggested that their loss is multifactorial and related to the characteristic features of these cells: complex morphology, high energy demand, high calcium flux, and dopamine metabolism [30]. Consequently, these neurons are particularly susceptible to various stressors, which contribute to their preferential loss (see Fig. 2).

SNpc DA neurons have one of the longest yet most dense arborisation of all neurons [31,32]. They project to the striatum, providing it with DA $[33,34]$. These neurons have long, thin, mostly unmyelineated axons [35] and up to 150,000 presynaptic terminals per neuron [30]. The high energy demand required to support synaptic activity, compensation for the potential risk of depolarization in the unmyelinated membrane, and axonal transport over long distances put a huge burden on the mitochondria. Interestingly, toxins that perturb the energy production and the axonal transport of mitochondria [36], cause parkinsonism in humans and preferential loss of DA neurons in animal models $[22,36,37]$. Finally, the large number of synapses increases the risk for local $\alpha$-synuclein $(\alpha$ syn) misfolding (see sections "Synaptic Dysfunction" and " $\alpha$ Synuclein Misfolding and Pathobiology").

SNpc DA neurons can fire autonomously and have specific calcium L-type Cav 1.3 channels that regulate this pacemaking activity $[38,39]$. The resulting high intracytosolic $\mathrm{Ca}^{2+}$ concentrations induce cellular stress, elevate the levels of reactive oxygen species (ROS), and increase demand for calcium buffering, which is handled by the endoplasmic reticulum (ER) and the mitochondria. Maintaining proper calcium homeostasis in such an environment increases again the 


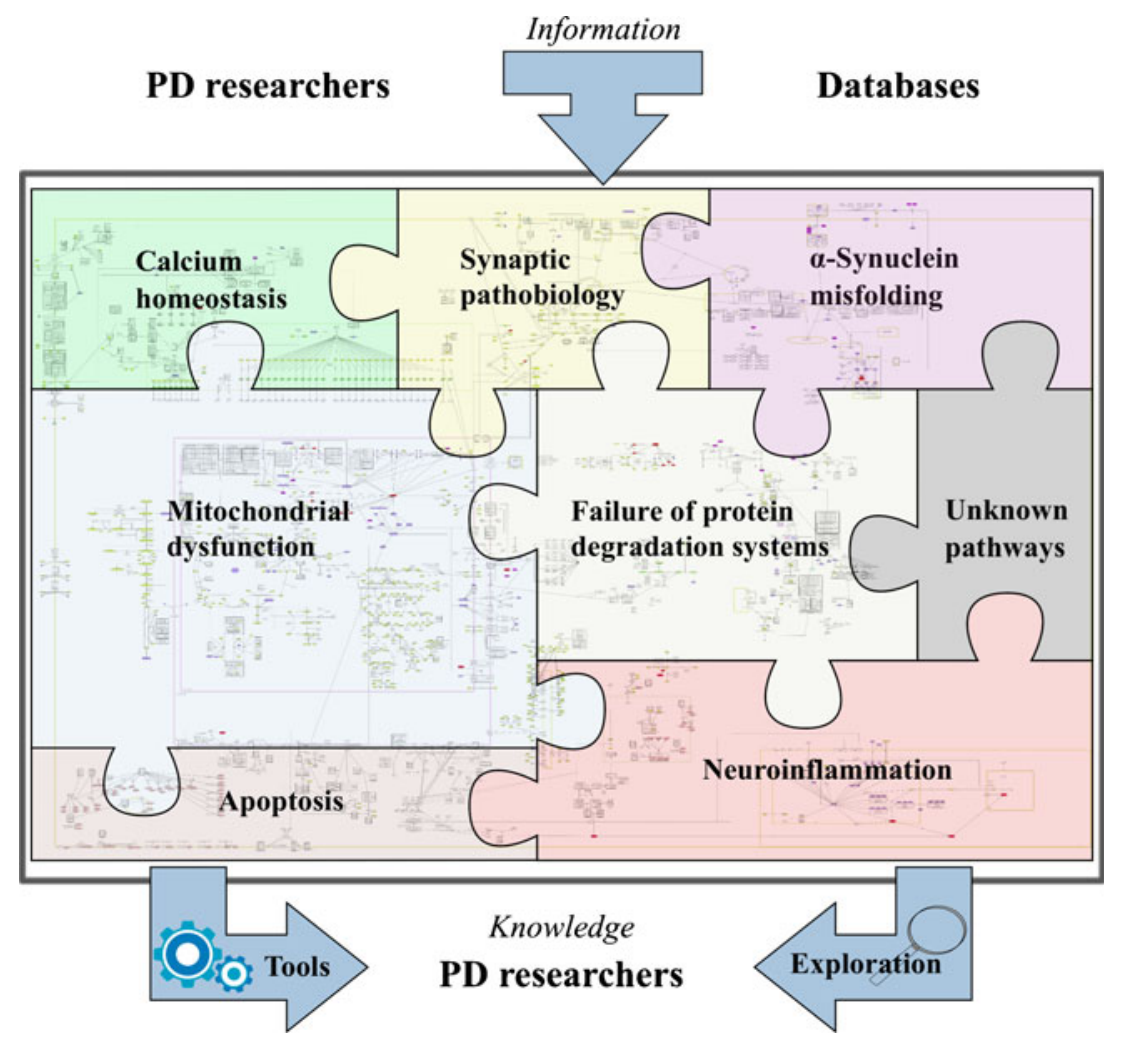

Fig. 1 The concept of Parkinson's disease map and its possibilities. The PD map is a knowledge repository bringing together different molecular mechanisms and pathways considered to be the key players in the disease. The current focus of the map is illustrated by the pieces in the "PD puzzle" These modules include synaptic and mitochondrial dysfunction, failure of protein degradation systems, $\alpha$-synuclein pathobiology and misfolding, and neuroinflammation. Processes important in PD-associated neurodegeneration, such calcium homeostasis or apoptosis, are discussed within their appropriate context in the main text, and included into the PD map pathways. The PD map is represented as a graph constructed with all gene-regulatory protein and metabolic interactions extracted from published data. Currently the map has 2,285 elements and 989 reactions supported by 429 articles and 254 entries from publicly available bioinformatic databases. It is compliant with

energy needs. In contrast, neighbouring dopamine neurons in the ventral tegmental area use $\mathrm{Na}^{+}$channels for pacemaking and are relatively spared in PD [37].

Cytosolic DA also contributes to the vulnerability of DA neurons, primarily because its metabolism induces oxidative and nitrative stress in an age-dependent manner [40-42]. Neurotoxicity of DA increases with its concentration, which is thought to be regulated by $\mathrm{Ca}^{2+}$ concentration [43]. Additionally, dopamine metabolism is involved in a number of PD-associated pathways, as it can impair synapse function, inhibit protein degradation and disturb mitochondrial dynamics by inhibiting the function of Parkin.

Ageing, the primary risk factor for PD, especially affects DA neurons (see Fig. 2). $\alpha$-Syn accumulation increases with age in the SNpc and correlates with the loss of DA neurons in non-human primates [42]. This could be linked to the age- standardized graphical representation, Systems Biology Graphical Notation $(S B G N)$ [265]. This standardized representation of the map could become a common language for the PD research community to discuss disease-related molecular mechanisms [5]. Detailed contents of the PD map are accessible at http://minerva.uni.lu/MapViewer/map?id=pdmap (Online resource 1) as an SBML file (Online resource 2) and in Payao [264]. The map can be updated with information from the PD research community, as well as by searching bioinformatics databases. Exploration and analysis of the content has the potential to broaden knowledge on the molecular processes in $\mathrm{PD}$, generate of new hypotheses on disease pathogenesis, or prioritize the most interesting areas and molecules for investigation. Approaches to facilitate this knowledge acquisition process are discussed in detail in the section "Annotation, enrichment and Analysis of the PD Map"

related impairment of the two protein degradation systems: the ubiquitin-proteasome system (UPS) [42] and the autophagy-lysosome system [44]. ROS accumulate in an ageing brain $[42,45]$, partially due to mitochondria dysfunction, as mitophagy ${ }^{2}$ is decreased with ageing $[45,46]$. Finally, the threshold required to trigger a neuroinflammatory response may decrease with age, since glial activation in SNpc increases in the ageing brain $[42,47]$.

\section{Synaptic Dysfunction}

The main function of a synapse is to establish a connection between neurons allowing communication via chemical or

\footnotetext{
${ }^{2}$ Mitophagy — autophagy of mitochondria.
} 


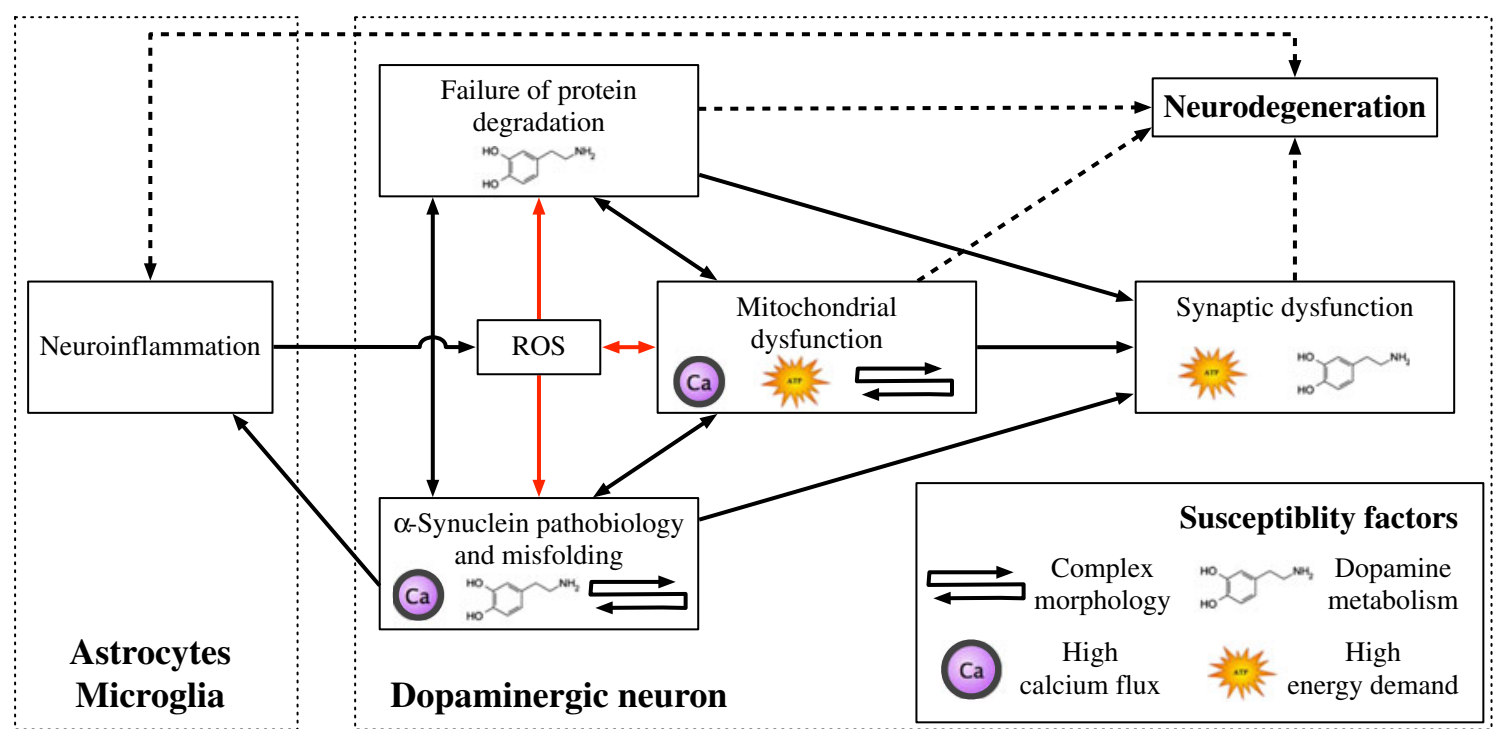

Fig. 2 Pathways implicated in PD and their relationship to susceptibility factors of SNpc DA neurons. The black arrows represent direct molecular interactions between the dysregulated pathways. Red arrows denote pathways affected by or generating ROS. Dashed lines represent

electric signals. The synapse has emerged as a neuronal structure highly susceptible to a variety of chronic insults [48-51]. Below, we discuss the increasing evidence indicating that synapses are also affected in PD, and that their dysfunction and demise contributes to the disease.

$\alpha$-Syn is a presynaptic protein. Point mutations, duplications or triplications of its gene are associated with familial PD [52-54]. In cultured neurons, it transiently associates with synaptic vesicles prior to neurotransmitter release, upon which it rapidly redistributes to the cytosol [55]. Association of $\alpha$-syn with the synaptic vesicle may occur through its binding to SNARE complex proteins [56], and, as shown in mice, $\alpha$-syn positively influences functional SNARE levels [57]. Similarly, upregulation of $\alpha$-syn in synapses and cell somas of cultured neurons protects against oxidative stress [58]. However, the protective effect of $\alpha$-syn is limited to a narrow concentration range, since high levels of $\alpha$-syn cause familial PD [53]. Even modest overexpression of $\alpha$-syn has been reported to markedly inhibit neurotransmitter release [59]. Also, $\alpha$-syn forms potentially pathogenic microaggregates in the synapse [60]. Another protein involved familial and sporadic PD, LRRK2, is also present in the synapse. Its experimentally induced upregulation or knockdown impairs the dynamics of synaptic vesicle release and recycling [61, 62]. However, the influence of mutated or dysfunctional LRRK2 on these processes in PD remains to be investigated.

A number of other PD-related pathological events might affect synapses. Synapses of the nigrostriatal pathway, with their high level of $\alpha$-syn and dopamine, are likely to be the major site of the formation of toxic adducts of $\alpha$-syn and indirect associations of these pathways and neurodegeneration. Susceptibility factors of SNpc DA neurons associated with a given pathway are indicated by their corresponding symbols

oxidized DA [40, 63, 64]. Furthermore, the energy demands of synapses may be compromised by dysfunctional mitochondrial respiration, turnover, or axonal transport [65]. Locally dysfunctional protein degradation and turnover may directly affect synaptic function and plasticity [66].

\section{Mitochondrial Dysfunction}

Mitochondria are highly dynamic organelles essential for a range of cellular processes including ATP production, ROS management, calcium homeostasis, and control of apoptosis. The maintenance of mitochondrial homoeostasis by mitophagy involves multiple factors ranging from the control of mitochondrial fusion and fission to mitochondrial motility [67]. These processes are strongly related to proteins involved in familial and sporadic PD [65, 68, 69].

A number of proteins associated with familial PD are related to mitochondrial function [70], with PINK1 and Parkin playing a particularly important role. Control of mitochondrial turnover and protection against oxidative stress are mediated via the kinase activity of PINK1 targeting Parkin [71], HTRA2 [72] and TRAP1[73] proteins. In turn, mitophagy is driven by PINK1-mediated translocation of Parkin from the cytosol to mitochondria [71, 74]. Importantly, both mitophagy [75, 76] and transcriptional control of mitochondrial biogenesis [77-79] depend on the E3 ubiquitin ligase activity of Parkin.

Familial PD genes are also implicated in ROS production by mitochondria. Mitochondrial respiration and calcium balance are perturbed by PINK1 deficiency [80, 81]. The resulting reduced mitochondrial calcium capacity and increased ROS 
could lower the threshold for mitochondrial outer membrane permeabilization (MOMP) and thereby increase the vulnerability for cell death [80]. Additional detrimental downstream effects of excessive ROS are mitochondrial DNA damage and inflammation [65, 82]. It has been suggested that DJ1 works in parallel to the PINK1-Parkin pathway to maintain mitochondrial function in the presence of an oxidative environment [83]. DJ1 was shown to interact with a mitochondrial protein mortalin, which maintains mitochondrial homeostasis and antagonizes oxidative stress injury [84]. Remarkably, Parkin overexpression has been demonstrated to prevent mitochondrial dysfunction caused by a mortalin knockdown [85].

Mitochondrial trafficking is necessary for proper energy supply. This process is particularly demanding in long axons of DA neurons. Recent findings suggest that mitochondrial transport may be affected in PD. Axonal transport of mitochondria along the microtubules is directly influenced by PINK1 through its supporting role in the kinesin motor complex [86]. Also, PINK1 and Parkin may play an important role in the process of quarantining the damaged mitochondria prior to their clearance [87]. However, the role of PINK1 in the dynamics of mitochondrial trafficking is not yet fully understood [88]. Mitochondrial trafficking may also be impaired by Parkin, $\alpha$-syn, or LRRK2 as they modulate microtubule stability [89-92], or by formation of $\alpha$-syn aggregates [93].

Finally, other proteins associated with familial PD have recently been linked to mitochondrial pathways. UCHL1mediated cell death can be attenuated by mitochondrial protein HTRA2 [94], ATP13A2 regulates mitochondrial bioenergetics through macroautophagy [95], VPS35 mediates vesicle transport between mitochondria and peroxisomes [96], and EIF4G1 is involved in stress related protection of mitochondria [97].

\section{Failure of Protein Degradation Systems}

In long-lived post-mitotic cells, such as neurons, the degradation systems assuring the removal of damaged, dysfunctional cellular structures play a key role in cellular homeostasis. These degradation systems are involved in the clearance of defective cellular structures such as misfolded or damaged proteins, and dysfunctional organelles such as defective mitochondria [98]. The two major degradation systems are the UPS and the autophagy-lysosome system. The complex machinery and biology of these two systems have been extensively reviewed elsewhere [66, 99-101]. The dysfunction of clearance systems, especially in the synapse, can lead to the accumulation of $\alpha$-syn and defective mitochondria. These, in turn, can interfere with proper synaptic function, lead to the formation of toxic assemblies or aggregates, or impair energy metabolism and cause oxidative stress.
Genetic and pathological evidence strongly indicate the involvement of defective clearance systems in PD [102-104]. Interestingly, patients with Gaucher's disease, a lysosomal storage disorder [105, 106], have an increased risk for PD and accumulate $\alpha$-syn in their brains [107]. Mutated forms of $\alpha$-syn have been reported to inhibit their own degradation by chaperone-mediated autophagy (CMA), while DA-modified $\alpha$-syn also blocks CMA degradation of other proteins [103]. Finally, pathological observations in PD autopsy brains and brains of PD animal models show an increased number of autophagy vacuoles and other autophagy markers $[108,109]$. Interestingly, neurons containing Lewy bodies (LB) were shown to have decreased UPS and lysosomal markers [110].

While this evidence demonstrates the involvement of cellular clearance mechanisms in PD, it is unclear whether that involvement is primarily beneficial or detrimental. It has been argued that exaggerated clearance activity may contribute to neuronal injury $[111,112]$. The predominant view, however, is that the removal of abnormal proteins and organelles is neuroprotective [102, 113-118].

\section{$\alpha$-Synuclein Misfolding and Pathobiology}

The pathobiology of $\alpha$-syn is implicated in a number of pathways involved in PD. $\alpha$-Syn is an intrinsically disordered protein [119], which can spontaneously and dynamically adopt either physiological or misfolded conformations. The latter contains $\beta$-sheet structure, which promotes oligomerisation and fibrilisation [120-122]. High-order oligomeric and pre-fibrillar forms are thought to be cytotoxic, while fibrillar and aggregated forms may be harmless, detoxified depositions $[119,123]$. This is still controversial, since familial PD $\alpha$-syn mutants promote both misfolding and aggregation of $\alpha$-syn, suggesting a pathological role of this process [103, 121, 124, 125].

Mutated, misfolded or overexpressed $\alpha$-syn is involved in a number of pathways associated with degeneration of SNpc DA neurons. It is thought to impair synapse function [126-129] and to affect the respiration, morphology and turnover of mitochondria [130-134]. Axonal transport might be impaired by misfolded $\alpha$-syn through perturbation of microtubule assembly [135-137], especially together with MAPT protein [138-143]. Also, oligomers of mutant $\alpha$-syn induce chronic ER stress [125, 144], which seems to precede actual neurodegeneration [145]. Finally, $\alpha$-syn degradation by CMA [146] might be perturbed by mutated or dopaminemodified $\alpha$-syn [103, 146, 147]. Reduction of lysosomal activity by $\alpha$-syn overexpression might lead to $\alpha$-syn accumulation [148], suggesting a vicious loop of CMA deficiency and $\alpha$-syn misfolding. The proteasome system has also been reported to be inhibited either by $\alpha$-syn mutants [149-151], or oligomers [152]. 
Recent studies suggest that $\alpha$-syn aggregates spread between cells and that this contributes to the PD disease process $[123,153]$. This hypothesis is supported by reports of protein inclusions detected in previously unaffected DA neurons grafted into the striatum of PD patients [154-156]. The existence of a neuron-to-neuron transfer mechanism for misfolded $\alpha$-syn has been shown in cell culture, primary mouse neurons and mouse models [157-159]. Moreover, it was observed that different types of cellular stress associated with PD pathogenesis, such as misfolded protein accumulation [160], proteasomal and mitochondrial dysfunction [161], are able to increase secretion of $\alpha$-syn and its aggregates.

It has been shown that exogenous $\alpha$-syn preformed fibrils might promote the aggregation of endogenous $\alpha$-syn in neuronal cells $[158,159,162]$ impairing neural function [158, 159]. Taken together, these results suggest that misfolded $\alpha$ syn can be secreted and taken up, introducing additional cellular stress and promoting further protein misfolding.

\section{Neuroinflammation}

Neuroinflammation and chronic activation of the immune system are pathological processes associated with all chronic neurodegenerative diseases, such as $\mathrm{PD}, \mathrm{AD}$ or multiple sclerosis [163]. Although the involvement of the adaptive immune system in PD-related neuroinflammation has been suggested [164, $165]$, in particular in the context of $\alpha$-syn and neuromelanin $[166,167]$, current research of neuroinflammation in PD focuses primarily on the innate immune system. Of particular interest are microglia $^{3}[168]$ and astrocytes ${ }^{4}[169,170]$.

Microglia constantly explore and monitor the local environment [171, 172], modulating the response of the immune system in relation to the level of their perturbation. At the first sign of stress, they produce and release anti-inflammatory cytokines and supportive growth factors [168]. Neurons play an active role in regulating the microglial response. Many of their products inhibit microglia activation by binding to specific microglial receptors [173-177].

The SNpc is a brain region that may be especially vulnerable to elevated neuroinflammation. The SNpc contains more microglia [178] and less astrocytes than other brain regions [179]. With a high microglial density promoting the inflammatory response, and low astroglial density to downregulate it, neuroinflammation in the SNpc may be particularly strong. Moreover, SNpc neurons contain neuromelanin, which has been shown to activate microglia [180] and could be another factor promoting neuroinflammation.

\footnotetext{
${ }^{3}$ Microglia - the most abundant of the resident macrophage populations in the CNS.

${ }^{4}$ Astrocytes - glial cells that play a supportive role for neurons and modulate microglia response.
}

The response of glial cells in the context of PD has been studied in humans, animal models and cell cultures. The presence of reactive microglia in human post-mortem brain tissue has been reported in PD patients [181] and in people exposed to MPTP [182]. In animal models of PD, microglial activation has been studied in primates [183], mice [184] and rats [185], supporting the notion that neuroinflammation is intrinsically associated with the PD pathological process. In cellular co-cultures of neuronal cells and microglia, neuronal injury drives microglia activation, which in turn enhances neurodegeneration [186].

In vitro systems demonstrate that the delicate balance between protective and detrimental effects of glial response might be disrupted by PD-related stress factors. Microglia can detect misfolded $\alpha$-syn [187, 188] and increase neurotoxicity by producing ROS and pro-inflammatory cytokines $[189,190]$. In turn, activated microglia expressing LRRK2 with a PD-related mutation produce more pro-inflammatory cytokines than corresponding cells expressing WT LRRK2 [191]. Deficiency in Parkin may indirectly promote microglia activation by increasing neuronal vulnerability for inflammation-related stress [192] and disturbing the neuron-microglia balance. Finally, DJ-1 deficiency in astrocytes might contribute to neurodegeneration by deregulating their neuroinflammatory response [193].

In summary, many in vitro PD models indicate a detrimental role of microglia. However, the situation in vivo is less clear, even though protective effects of anti-inflammatory compounds such as minocycline have been reported in models of PD [194].

\section{Neuronal Death Through Apoptosis-Related Mechanisms}

Degeneration of DA neurons is the final consequence of dysregulated cellular processes, leading to neuronal death [195]. Neurodegeneration by apoptosis typically proceeds through one of two signalling cascades, termed the intrinsic and extrinsic pathways [196, 197].

The intrinsic pathway can be induced by intracellular stress, leading to MOMP that is controlled through proteins of the BCL-2 family. As a result, cytochrome $c$ is released from the mitochondrial intermembrane space, leading to formation of an apoptosome and subsequent execution of apoptosis by activation of caspases 3 and 7 . Studies in animal models of PD suggest the BCL-2 family is a key target for attenuating neurodegeneration of DA neurons [198-202].

Additionally, an important link between PD and the activation of apoptosis comes from studies investigating the roles of familial PD genes. It has been shown that diseaserelated LRRK2 mutations R1441C, Y1699C and G2019S promote mitochondria-dependent apoptosis [203]. PINK1 and Parkin, in turn, protect against stress-induced cytochrome 
$c$ release, while their mutations might fail to attenuate basal neuronal pro-apoptotic activity [204-206]. Importantly, failure of the protein degradation system could also contribute to apoptosis via the intrinsic pathway. It has been proposed that lysosome membrane permeabilization is induced by ROS and occurs upstream and downstream of MOMP [207, 208]. Finally, DA-mediated activation of the intrinsic pathway may contribute to selective DA neuron degeneration [209].

The extrinsic apoptosis pathway is activated by extracellular signalling, and diverges into two sub-pathways: one directly activating caspase 3 and 7, the other causing MOMP. Neuroinflammation could be a major factor in this process $[165,187,210]$, promoting neuronal apoptosis either by oxidative insults [211] or by pro-inflammatory cytokines [212, 213].

In summary, both apoptosis pathways appear to be the convergence point of different pathways dysregulated in PD. Still, therapeutic interventions may be most efficacious in maintaining DA neuron functionality if aimed at the upstream events of apoptosis. Indeed, as the apoptotic process is advanced, the intervention may be too late.

\section{Annotation, Enrichment and Analysis of the PD Map}

Dysregulated pathways implicated in PD are strongly coupled, and their interconnections need to be represented in an integrated and comprehensive way to be studied efficiently. Our PD map allows navigation through information on PDassociated mechanisms, and constitutes an interface to wellestablished tools and methods for updating, enriching, and analysing its contents (see Fig. 3).

\section{Annotation of the PD Map Using Bioinformatic Databases}

We have enriched the elements of the PD map using a number of publicly available databases [214-230]. Information on official gene symbol, synonyms, description and chromosomal location; association with biological processes and diseases; or molecular interacting partners have been embedded within the map. Annotation of the contents of the PD map facilitates the knowledge exploration by providing additional information about map elements and their interactions, and is easily accessible online (see Fig. 3b for illustration and Online resource 1 for details).

\section{Exploration of the Map Using Integrative Expression Analysis}

Recently, a variety of PD-related large-scale datasets have become publicly available, including microarray gene expression data for human post mortem samples from different regions of the brain [231-234], human whole-blood samples [235], and samples from animal [236] and cell culture models [237]. This experimental data can be visualized on the PD map or used to predict new map elements and interactions [238-240].

Visualization of gene deregulation in PD-related microarray datasets [231-234] is possible via a variety of methods for candidate disease gene or protein prioritizations [241-244]. We have chosen an approach combining significance scores [245] for differentially expressed genes in multiple studies, and prepared a colour-coded version of the map highlighting upregulation in green and downregulation in red (see the online PD map and Online resource 1). This gives an immediate overview of pathways that are affected by dysregulated genes.

One of the major advantages of the PD map is the possibility to predict new elements and interactions on the basis of the map contents and experimental data. To achieve this, publicly available human molecular interaction data [242] are obtained for the PD map elements, extending the number of interactions. Then, an automated, graph-theoretic approach [243] prioritizes candidate disease proteins that are densely interconnected in the extended PD map, and whose gene expression levels are differentially expressed in the microarray PD samples. We have combined the abovementioned experimental microarray [231-234] and protein-protein interaction data [242] to demonstrate the usage of this approach. The extended PD map containing the prioritized new proteins can be found in Online resource 1.

\section{PD Map as a Network: from Structural Analysis to Kinetic Models}

The PD map is a large, complex network integrating metabolic reactions, gene regulation, and signalling processes. Exploring how different elements in the network may influence each other is difficult and non-intuitive. Graphtheoretical methods aim to bridge the gap between our understanding of the role of single elements in a cellular network and the properties of this network as whole [246, 247]. These methods aim to identify key network nodes (genes, proteins), edges (molecular interactions) or modules ${ }^{5}$ (subnetworks) [246].

Basic properties of individual network elements such as node centrality ${ }^{6}$ indicate their global role in the whole network. In turn, analysis of inter-modular communication ${ }^{\mathrm{f}}$ in

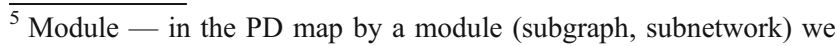
understand elements and interactions participating in the same pathway or serve similar biological function. Inter-modular communication denotes all interactions linking different modules.

${ }^{6}$ Node centrality - a measure describing how important a given node is for the connectivity of the entire network.
} 


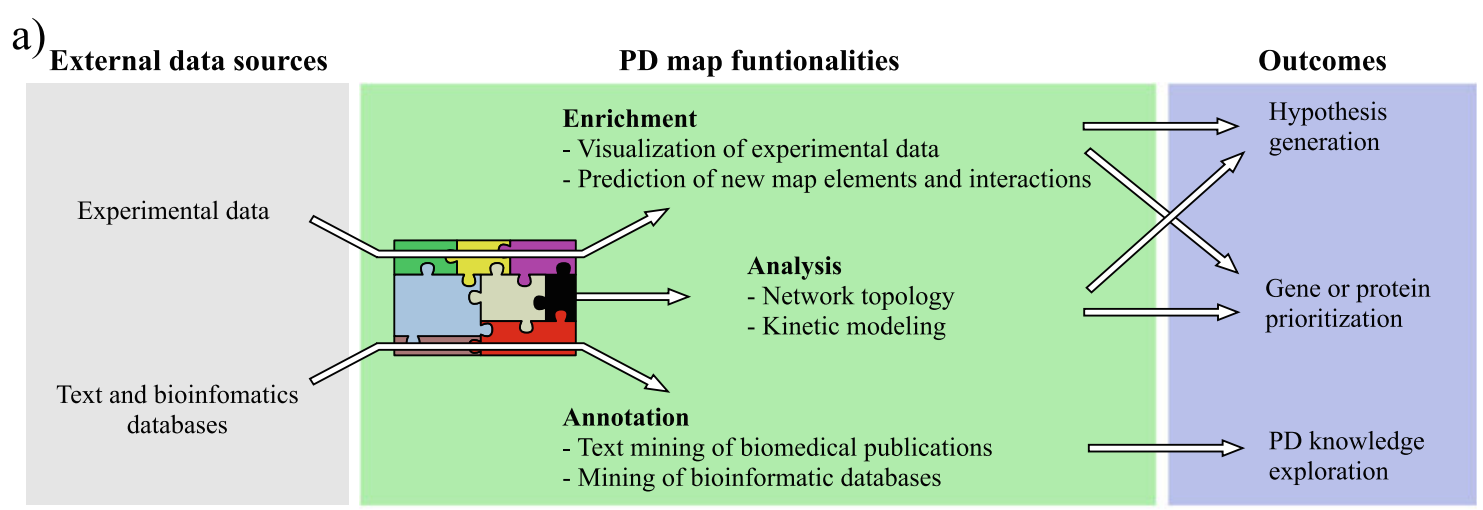

b)

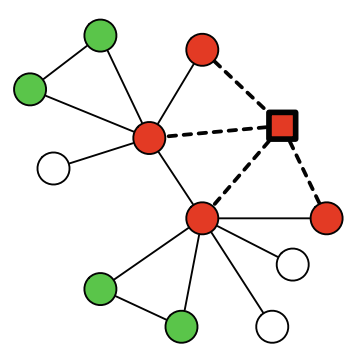

Analysis

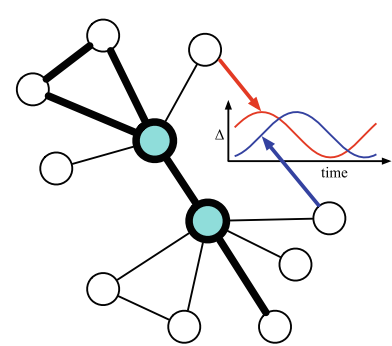

Annotation

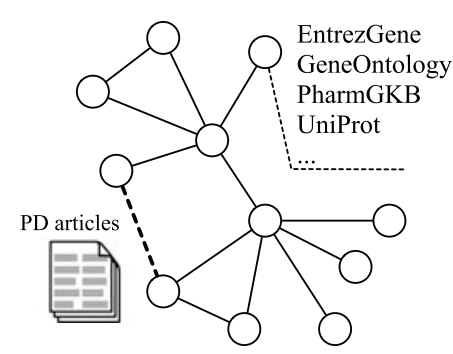

Fig. 3 The workflow and an illustration of PD map functionalities. a The PD map can be automatically enriched with experimental data and annotated with information from text and bioinformatics databases. The analysis requires no external data sources. b A simplified representation of the PD map is given, with circles (nodes) as map elements and lines (edges) as interactions (uni- or bi-directional). Enrichment: green and red nodes represent up- and downregulated genes, respectively, derived from experimental data; a predicted new map component (square) shares interaction with existing map components (dashed lines) and matches their expression profile. Analysis: nodes with high centrality

the network indicates a how given molecule, complex or interaction can affect communication between modules [248, 249]. More advanced, functional dependencies between elements in the network can be revealed by methods exploring the relationships of all possible paths between network elements and selected molecular dysfunctions [250] (see Fig. 3b for illustration). Examples of network analysis applied to the PD map can be found in Online resource 1.

Most of the connections on the PD map depict real physical interactions between biomolecules. Currently, the PD map contains no information on kinetics of these interactions; however, they can be easily assigned and analysed mathematically [251]. The PD map is compliant with the Systems Biology Markup Language (SBML) standard [252], used by commonly available software to build kinetic models and run simulations [253]. Although assigning kinetic parameters to all interactions in the PD map is a truly challenging task, describing kinetics of a certain process representing a module within the PD map is feasible. In-depth analysis of the dynamics of a process can provide insight as to how elements of (blue) play a key role in the network topology and indicate molecules regulating many processes; detection of paths (thick lines) highlights non-trivial relations between elements of a biological process; kinetic modelling reveals temporal dependencies between behaviour of different molecules. Annotation: text mining of PD-related articles suggests new interactions in the map (thick dashed line) and facilitates handling of a huge number of publications; each map element is annotated with information from various bioinformatics databases giving easy access to information about interesting elements

the process change quantitatively and over time (see Fig. $3 \mathrm{~b}$ for illustration) and assess their influence on the related components in the map. This can lead to new hypotheses that are impossible to discover by visual examination or analysis of static network topology [254]. There are many successful examples, where similar bottom-up modelling has been applied to neurobiology related systems [255-258].

In summary, structural network analysis allows for detection of elements key to PD pathogenesis represented in the map. This can serve as a basis for new hypotheses and prioritization of targets for further investigation.

\section{Conclusions and Perspectives}

$\mathrm{PD}$ is a neurodegenerative disease involving a complex interplay of environmental and genetic factors. It becomes increasingly important to develop new approaches to organize and explore the exploding knowledge of this field. The PD map is a computerbased knowledge repository, representing diagrammatically 
molecular mechanisms of PD in a structured and standardized way. It can be linked to bioinformatics tools facilitating exploration and updating the contents of the map using bioinformatic annotations.

The main insights into molecular pathology of PD come from studies on familial PD and GWAS. In the future, massive use of next-generation sequencing will provide even more data that might contribute to PD. The PD map facilitates integration and visualization of large experimental datasets, allowing analyzing them in the context of disease mechanisms.

Discovering causal factors of PD pathogenesis is difficult because molecular pathways dysregulated in neurodegeneration are interconnected and influence each other. Analysis of the topology and dynamics of molecular interactions within and across different pathways represented in the PD map may help to uncover key factors in PD pathology. For instance, the role of neuroinflammation in the pathological cascade in PD remains unclear, while the apoptosis, clearly a downstream factor of PD, involves other mechanisms implicated in PD, like protein degradation or mitochondrial quality control. Consequential steps of PD pathology can be elucidated by the global, systems level analysis of all implicated factors.

The map has reached substantial size and complexity. Keeping it up-to-date and refining it with limited resources will be a challenge. We foresee the PD map as a crowdsourcing project, where an interested and knowledgeable research community is engaged in solving a problem [259-262], similar to WikiPathways or Payao [263, 264], but focused on disease-related mechanisms. Thus, the PD community will easily explore and curate the PD-related knowledge in an online manner, ensuring that individual contributions are recognized.

Acknowledgments We are grateful to Angela Hogan for language correction assistance.

Conflict of interest The authors declare that they have no conflict of interest.

Open Access This article is distributed under the terms of the Creative Commons Attribution License which permits any use, distribution, and reproduction in any medium, provided the original author(s) and the source are credited.

\section{References}

1. Obeso JA, Rodriguez-Oroz MC, Goetz CG et al (2010) Missing pieces in the Parkinson's disease puzzle. Nat Med 16:653-661. doi: $10.1038 / \mathrm{nm} .2165$

2. Caron E, Ghosh S, Matsuoka Y et al (2010) A comprehensive map of the mTOR signaling network. Mol Syst Biol 6:453. doi:10.1038/ msb. 2010.108

3. Mizuno S, Iijima R, Ogishima S et al (2012) AlzPathway: a comprehensive map of signaling pathways of Alzheimer's disease. BMC Syst Biol 6:52. doi:10.1186/1752-0509-6-52
4. Ghosh S, Matsuoka Y, Asai Y et al (2011) Software for systems biology: from tools to integrated platforms. Nat Rev Genet 12:821832

5. Kitano H, Ghosh S, Matsuoka Y (2011) Social engineering for virtual "big science" in systems biology. Nat Chem Biol 7:323326

6. Lees AJ, Hardy J, Revesz T (2009) Parkinson's disease. Lancet 373:2055-2066. doi:10.1016/S0140-6736(09)60492-X

7. Jankovic J (2008) Parkinson's disease: clinical features and diagnosis. J Neurol Neurosurg Psychiatry 79:368-376. doi:10.1136/ jnnp.2007.131045

8. Meissner WG, Frasier M, Gasser T et al (2011) Priorities in Parkinson's disease research. Nat Rev Drug Disc 10:377-393. doi: $10.1038 / \mathrm{nrd} 3430$

9. Dick FD, De Palma G, Ahmadi A et al (2007) Environmental risk factors for Parkinson's disease and parkinsonism: the Geoparkinson study. Occup Environ Med 64:666-672. doi:10.1136/ oem.2006.027003

10. Goldman SM, Tanner CM, Oakes D et al (2006) Head injury and Parkinson's disease risk in twins. Ann Neurol 60:65-72. doi:10.1002/ ana. 20882

11. Ritz B, Ascherio A, Checkoway H et al (2007) Pooled analysis of tobacco use and risk of Parkinson disease. Arch Neurol 64:990 997. doi:10.1001/archneur.64.7.990

12. Hu G, Bidel S, Jousilahti P et al (2007) Coffee and tea consumption and the risk of Parkinson's disease. Mov Disord 22:22422248. doi: $10.1002 / \mathrm{mds} .21706$

13. Saunders-Pullman R (2003) Estrogens and Parkinson disease: neuroprotective, symptomatic, neither, or both? Endocrine 21:8187. doi:10.1385/ENDO:21:1:81

14. Klein C, Westenberger A (2012) Genetics of Parkinson's disease. Cold Spring Harb Perspect Med 2:a008888. doi:10.1101/ cshperspect.a008888

15. Marques SCF, Oliveira CR, Pereira CMF, Outeiro TF (2011) Epigenetics in neurodegeneration: a new layer of complexity. Prog Neuropsychopharmacol Biol Psychiatry 35:348-355. doi:10.1016/j.pnpbp. 2010.08.008

16. Migliore L, Coppedè F (2009) Genetics, environmental factors and the emerging role of epigenetics in neurodegenerative diseases. Mutat Res 667:82-97. doi:10.1016/j.mrfmmm.2008.10.011

17. Schapira AHV (2011) Aetiopathogenesis of Parkinson's disease. J Neurol 258:S307-S310. doi:10.1007/s00415-011-6016-y

18. Priyadarshi A, Khuder SA, Schaub EA, Priyadarshi SS (2001) Environmental risk factors and Parkinson's disease: a metaanalysis. Environ Res 86:122-127. doi:10.1006/enrs.2001.4264

19. Dick FD (2006) Parkinson's disease and pesticide exposures. Br Med Bull 79-80:219-231. doi:10.1093/bmb/ld1018

20. Davis GC, Williams AC, Markey SP et al (1979) Chronic Parkinsonism secondary to intravenous injection of meperidine analogues. Psychiatry Res 1:249-254

21. Langston JW, Ballard P, Tetrud JW, Irwin I (1983) Chronic Parkinsonism in humans due to a product of meperidine-analog synthesis. Science 219:979-980

22. Betarbet R, Sherer TB, MacKenzie G et al (2000) Chronic systemic pesticide exposure reproduces features of Parkinson's disease. Nat Neurosci 3:1301-1306. doi:10.1038/81834

23. Thiruchelvam M, Richfield EK, Baggs RB et al (2000) The nigrostriatal dopaminergic system as a preferential target of repeated exposures to combined paraquat and maneb: implications for Parkinson's disease. J Neurosci 20:9207-9214

24. Gash DM, Rutland K, Hudson NL et al (2008) Trichloroethylene: Parkinsonism and complex 1 mitochondrial neurotoxicity. Ann Neurol 63:184-192. doi:10.1002/ana.21288

25. Goldman SM (2010) Trichloroethylene and Parkinson's disease: dissolving the puzzle. Expert Rev Neurother 10:835-837. doi:10.1586/ ern.10.61 
26. Braak H, Del Tredici K, Rüb U et al (2003) Staging of brain pathology related to sporadic Parkinson's disease. Neurobiol Aging 24:197-211

27. Poulopoulos M, Levy OA, Alcalay RN (2012) The neuropathology of genetic Parkinson's disease. Mov Disord 000:1-12. doi:10.1002/ mds. 24962

28. Wolters EC (2009) Non-motor extranigral signs and symptoms in Parkinson's disease. Parkinsonism \& Relat Disord 15(Suppl 3): S6-S12. doi:10.1016/S1353-8020(09)70770-9

29. Ferrer I, López-Gonzalez I, Carmona M et al (2012) Neurochemistry and the non-motor aspects of PD. Neurobiol Dis 46:508-526. doi:10.1016/j.nbd.2011.10.019

30. Sulzer D (2007) Multiple hit hypotheses for dopamine neuron loss in Parkinson's disease. Trends Neurosci 30:244-250. doi:10.1016/ j.tins.2007.03.009

31. Matsuda W, Furuta T, Nakamura KC et al (2009) Single nigrostriatal dopaminergic neurons form widely spread and highly dense axonal arborizations in the neostriatum. J Neurosci 29:444-453

32. Matsuda W (2012) Imaging of dopaminergic neurons and the implications for Parkinson's disease. Syst Biol Parkinson's Dis. doi:10.1007/978-1-4614-3411-5

33. Parent M, Parent A (2006) Relationship between axonal collateralization and neuronal degeneration in basal ganglia. $\mathrm{J}$ Neural Transm Suppl 85-8

34. Schmitz Y, Luccarelli J, Kim M et al (2009) Glutamate controls growth rate and branching of dopaminergic axons. J Neurosci 29:11973-11981. doi:10.1523/JNEUROSCI.2927-09.2009

35. Braak H, Bohl JR, Müller CM et al (2006) Stanley Fahn Lecture 2005: the staging procedure for the inclusion body pathology associated with sporadic Parkinson's disease reconsidered. Mov Disord 21:2042-2051. doi:10.1002/mds.21065

36. Kim-Han JS, Antenor-Dorsey JA, O'Malley KL (2011) The Parkinsonian mimetic, MPP+, specifically impairs mitochondrial transport in dopamine axons. J Neurosci 31:7212-7221. doi:10.1523/JNEUROSCI.0711-11.2011

37. Dauer W, Przedborski S (2003) Parkinson's disease: mechanisms and models. Neuron 39:889-909

38. Chan CS, Guzman JN, Ilijic E et al (2007) "Rejuvenation" protects neurons in mouse models of Parkinson's disease. Nature 447:1081-1086. doi:10.1038/nature05865

39. Surmeier DJ, Guzman JN, Sanchez-Padilla J, Schumacker PT (2011) The role of calcium and mitochondrial oxidant stress in the loss of substantia nigra pars compacta dopaminergic neurons in Parkinson's disease. Neuroscience 198:221-231

40. Asanuma M, Miyazaki I, Ogawa N (2003) Dopamine- or L-DOPAinduced neurotoxicity: the role of dopamine quinone formation and tyrosinase in a model of Parkinson's disease. Neurotox Res 5:165-176

41. Cantuti-Castelvetri I, Shukitt-Hale B, Joseph JA (2003) Dopamine neurotoxicity: age-dependent behavioral and histological effects. Neurobiol aging 24:697-706

42. Collier TJ, Kanaan NM, Kordower JH (2011) Ageing as a primary risk factor for Parkinson's disease: evidence from studies of nonhuman primates. Nat Rev Neurosci 12:359-366. doi:10.1038/ nrn3039

43. Mosharov EV, Larsen KE, Kanter E et al (2009) Interplay between cytosolic dopamine, calcium, and alpha-synuclein causes selective death of substantia nigra neurons. Neuron 62:218-229. doi:10.1016/j.neuron.2009.01.033

44. Rubinsztein DC, Mariño G, Kroemer G (2011) Autophagy and aging. Cell 146:682-695. doi:10.1016/j.cell.2011.07.030

45. Mammucari C, Rizzuto R (2010) Signaling pathways in mitochondrial dysfunction and aging. Mech Ageing Dev 131:536543. doi:10.1016/j.mad.2010.07.003

46. Green DR, Galluzzi L, Kroemer G (2011) Mitochondria and the autophagy-inflammation-cell death axis in organismal aging. Science 333:1109-1112. doi:10.1126/science.1201940
47. Venkateshappa C, Harish G, Mythri RB et al (2012) Increased oxidative damage and decreased antioxidant function in aging human substantia nigra compared to striatum: implications for Parkinson's disease. Neurochem Res 37:358-369. doi:10.1007/ s11064-011-0619-7

48. Mallucci GR (2009) Prion neurodegeneration: starts and stops at the synapse. Prion 3:195-201

49. Sisková Z, Sanyal NK, Orban A et al (2010) Reactive hypertrophy of synaptic varicosities within the hippocampus of prion-infected mice. Biochem Soc Trans 38:471-475

50. Masliah E (1998) Mechanisms of synaptic pathology in Alzheimer's disease. J Neural Transm Suppl 53:147-158

51. Palop JJ, Mucke L (2010) Amyloid-beta-induced neuronal dysfunction in Alzheimer's disease: from synapses toward neural networks. Nat Neurosci 13:812-818

52. Polymeropoulos MH, Lavedan C, Leroy E et al (1997) Mutation in the alpha-synuclein gene identified in families with Parkinson's disease. Science 276:2045-2047

53. Singleton AB, Farrer MJ, Johnson J et al (2003) alpha-Synuclein locus triplication causes Parkinson's disease. Science 302:841. doi:10.1126/science. 1090278

54. Simón-Sánchez J, Schulte C, Bras JM et al (2009) Genome-wide association study reveals genetic risk underlying Parkinson's disease. Nat Genet 41:1308-1312

55. Fortin DL, Nemani VM, Voglmaier SM et al (2005) Neural activity controls the synaptic accumulation of alpha-synuclein. J Neurosci 25:10913-10921. doi:10.1523/JNEUROSCI.2922-05.2005

56. Burré J, Sharma M, Tsetsenis T et al (2010) Alpha-synuclein promotes SNARE-complex assembly in vivo and in vitro. Science 329:1663-1667

57. Chandra S, Gallardo G, Fernández-Chacón R et al (2005) Alphasynuclein cooperates with CSPalpha in preventing neurodegeneration. Cell 123:383-396

58. Quilty MC, King AE, Gai W-P et al (2006) Alpha-synuclein is upregulated in neurones in response to chronic oxidative stress and is associated with neuroprotection. Exp Neurol 199:249-256

59. Nemani VM, Lu W, Berge V et al (2010) Increased expression of alpha-synuclein reduces neurotransmitter release by inhibiting synaptic vesicle reclustering after endocytosis. Neuron 65:66-79

60. Schulz-Schaeffer WJ (2010) The synaptic pathology of $\alpha$ synuclein aggregation in dementia with Lewy bodies, Parkinson's disease and Parkinson's disease dementia. Acta Neuropathologica 120:131-143

61. Piccoli G, Condliffe SB, Bauer M et al (2011) LRRK2 controls synaptic vesicle storage and mobilization within the recycling pool. J Neurosci 31:2225-2237

62. Shin N, Jeong H, Kwon J et al (2008) LRRK2 regulates synaptic vesicle endocytosis. Exp Cell Res 314:2055-2065

63. Conway KA, Rochet JC, Bieganski RM, Lansbury PT (2001) Kinetic stabilization of the alpha-synuclein protofibril by a dopamine-alpha-synuclein adduct. Science 294:1346-1349. doi:10.1126/science.1063522

64. Leong SL, Cappai R, Barnham KJ, Pham CLL (2009) Modulation of alpha-synuclein aggregation by dopamine: a review. Neurochem Res 34:1838-1846

65. Perier C, Vila M (2012) Mitochondrial biology and Parkinson's disease. Cold Spring Harb Perspect Med 2:a009332. doi:10.1101/ cshperspect.a009332

66. Tai H-C, Schuman EM (2008) Ubiquitin, the proteasome and protein degradation in neuronal function and dysfunction. Nat Rev Neurosci 9:826-838

67. Youle RJ, Van der Bliek AM (2012) Mitochondrial fission, fusion, and stress. Science 337:1062-1065. doi:10.1126/science.1219855

68. Schapira AHV, Cooper JM, Dexter D et al (1990) Mitochondrial complex I deficiency in Parkinson's disease. J Neurochem 54: 823-827 
69. Parker WD, Boyson SJ, Parks JK (1989) Abnormalities of the electron transport chain in idiopathic Parkinson's disease. Ann Neurol 26:719-723. doi:10.1002/ana.410260606

70. Koopman W, Willems P (2012) Monogenic mitochondrial disorders. New Engl J Med

71. Matsuda N, Sato S, Shiba K et al (2010) PINK1 stabilized by mitochondrial depolarization recruits Parkin to damaged mitochondria and activates latent Parkin for mitophagy. J Cell Biol 189:211-221. doi:10.1083/jcb.200910140

72. Plun-Favreau H, Klupsch K, Moisoi N et al (2007) The mitochondrial protease HtrA2 is regulated by Parkinson's disease-associated kinase PINK1. Nature Cell Biol 9:1243-1252. doi:10.1038/ ncb1644

73. Pridgeon JW, Olzmann J a, Chin L-S, Li L (2007) PINK1 protects against oxidative stress by phosphorylating mitochondrial chaperone TRAP1. PLoS Biol 5:e172. doi:10.1371/journal.pbio. 0050172

74. Chan NC, Salazar AM, Pham AH et al (2011) Broad activation of the ubiquitin-proteasome system by Parkin is critical for mitophagy. Hum Mol Genet 20:1726-1737. doi:10.1093/hmg/ddr048

75. Gegg ME, Cooper JM, Chau K-Y et al (2010) Mitofusin 1 and mitofusin 2 are ubiquitinated in a PINK1/parkin-dependent manner upon induction of mitophagy. Hum Mol Genet 19:4861-4870. doi: $10.1093 / \mathrm{hmg} / \mathrm{ddq} 419$

76. Geisler S, Holmström KM, Skujat D et al (2010) PINK1/Parkinmediated mitophagy is dependent on VDAC1 and p62/SQSTM1. Nature Cell Biol 12:119-131. doi:10.1038/ncb2012

77. Shin J-H, Ko HS, Kang H et al (2011) PARIS (ZNF746) Repression of PGC- $1 \alpha$ contributes to neurodegeneration in Parkinson's disease. Cell 144:689-702. doi:10.1016/j.cell.2011.02.010

78. Scarpulla RC (2008) Transcriptional paradigms in mammalian mitochondrial biogenesis and function. Physiol Rev 88:611-638. doi:10.1152/physrev.00025.2007

79. Ryan MT, Hoogenraad NJ (2007) Mitochondrial-nuclear communications. Annu Rev Biochem 76:701-722. doi:10.1146/annurev. biochem.76.052305.091720

80. Gandhi S, Wood-Kaczmar A, Yao Z et al (2009) PINK1associated Parkinson's disease is caused by neuronal vulnerability to calcium-induced cell death. Molecular Cell 33:627-638. doi:10.1016/j.molcel.2009.02.013

81. Yao Z, Gandhi S, Burchell VS et al (2011) Cell metabolism affects selective vulnerability in PINK1-associated Parkinson's disease. J Cell Sci 124:4194-4202. doi:10.1242/jcs.088260

82. Tschopp J (2011) Mitochondria: Sovereign of inflammation? Eur J Immunol 41:1196-1202

83. Thomas KJ, McCoy MK, Blackinton J et al (2011) DJ-1 acts in parallel to the PINK1/parkin pathway to control mitochondrial function and autophagy. Hum Mol Genet 20:40-50. doi:10.1093/ hmg/ddq430

84. Burbulla LF, Schelling C, Kato H et al (2010) Dissecting the role of the mitochondrial chaperone mortalin in Parkinson's disease: functional impact of disease-related variants on mitochondrial homeostasis. Hum Mol Genet 19:4437-4452. doi:10.1093/hmg/ ddq370

85. Yang H, Zhou X, Liu X et al (2011) Mitochondrial dysfunction induced by knockdown of mortalin is rescued by Parkin. Biochem Biophys Res Commun 410:114-120. doi:10.1016/j.bbrc.2011.05.116

86. Weihofen A, Thomas KJ, Ostaszewski BL et al (2009) Pink1 forms a multiprotein complex with Miro and Milton, linking Pink 1 function to mitochondrial trafficking. Biochemistry 48:2045-2052. doi:10.1021/bi8019178

87. Wang X, Winter D, Ashrafi G et al (2011) PINK1 and Parkin target Miro for phosphorylation and degradation to arrest mitochondrial motility. Cell 147:893-906. doi:10.1016/j.cell.2011.10.018

88. Pilsl A, Winklhofer KF (2012) Parkin, PINK1 and mitochondrial integrity: emerging concepts of mitochondrial dysfunction in
Parkinson's disease. Acta Neuropathol 123:173-188. doi:10.1007/ s00401-011-0902-3

89. Sheng Z-H, Cai Q (2012) Mitochondrial transport in neurons: impact on synaptic homeostasis and neurodegeneration. Nat Rev Neurosci 13:77-93. doi:10.1038/nrn3156

90. Lee H-J, Khoshaghideh F, Lee S, Lee S-J (2006) Impairment of microtubule-dependent trafficking by overexpression of alphasynuclein. Eur J Neurosci 24:3153-3162. doi:10.1111/j.14609568.2006.05210.x

91. Yang F, Jiang Q, Zhao J et al (2005) Parkin stabilizes microtubules through strong binding mediated by three independent domains. J Biol Chem 280:17154-17162. doi:10.1074/jbc.M500843200

92. Gillardon F (2009) Leucine-rich repeat kinase 2 phosphorylates brain tubulin-beta isoforms and modulates microtubule stability - a point of convergence in parkinsonian neurodegeneration? J Neurochem 110:1514-1522. doi:10.1111/j.1471-4159.2009.06235.x

93. Borland MK, Trimmer PA, Rubinstein JD et al (2008) Chronic, low-dose rotenone reproduces Lewy neurites found in early stages of Parkinson's disease, reduces mitochondrial movement and slowly kills differentiated SH-SY5Y neural cells. Mol Neurodegener 3:21. doi:10.1186/1750-1326-3-21

94. Park D-W, Nam M-K, Rhim H (2011) The serine protease HtrA2 cleaves UCH-L1 and inhibits its hydrolase activity: implication in the UCH-L1-mediated cell death. Biochem Biophys Res Commun 415:24-29. doi:10.1016/j.bbrc.2011.09.148

95. Gusdon AM, Zhu J, Van Houten B, Chu CT (2012) ATP13A2 regulates mitochondrial bioenergetics through macroautophagy. Neurobiol Dis 45:962-972. doi:10.1016/j.nbd.2011.12.015

96. Braschi E, Goyon V, Zunino R et al (2010) Vps35 mediates vesicle transport between the mitochondria and peroxisomes. Curr Biol 20:1310-1315. doi:10.1016/j.cub.2010.05.066

97. Chartier-Harlin M-C, Dachsel JC, Vilariño-Güell C et al (2011) Translation initiator EIF4G1 mutations in familial Parkinson disease. Am J Hum Genet 89:398-406. doi:10.1016/j.ajhg.2011.08.009

98. Lee J, Giordano S, Zhang J (2012) Autophagy, mitochondria and oxidative stress: cross-talk and redox signalling. Biochem $\mathrm{J}$ 441:523-540. doi:10.1042/BJ20111451

99. Korolchuk VI, Menzies FM, Rubinsztein DC (2010) Mechanisms of cross-talk between the ubiquitin-proteasome and autophagylysosome systems. FEBS Lett 584:1393-1398

100. Kroemer G, Mariño G, Levine B (2010) Autophagy and the integrated stress response. Molecular cell 40:280-293. doi:10.1016/ j.molcel.2010.09.023

101. Ravikumar B, Sarkar S, Davies JE et al (2010) Regulation of mammalian autophagy in physiology and pathophysiology. Physiol Rev 90:1383-1435. doi:10.1152/physrev.00030.2009

102. Harris H, Rubinsztein DC (2011) Control of autophagy as a therapy for neurodegenerative disease. Nat Rev Neurol 8:108117. doi:10.1038/nrneurol.2011.200

103. Martinez-Vicente M, Talloczy Z, Kaushik S et al (2008) Dopamine-modified alpha-synuclein blocks chaperone-mediated autophagy. J Clin Investig 118:777-788. doi:10.1172/ JCI32806DS1

104. Nalls MA, Plagnol V, Hernandez DG et al (2011) Imputation of sequence variants for identification of genetic risks for Parkinson's disease: a meta-analysis of genome-wide association studies. Lancet 377:641-649

105. Grabowski GA (2008) Phenotype, diagnosis, and treatment of Gaucher's disease. Lancet 372:1263-1271

106. Yap TL, Gruschus JM, Velayati A et al (2011) \{alpha\}-Synuclein interacts with glucocerebrosidase providing a molecular link between Parkinson and Gaucher diseases. J Biol Chem 286:28080 28088. doi:10.1074/jbc.M111.237859

107. Westbroek W, Gustafson AM, Sidransky E (2011) Exploring the link between glucocerebrosidase mutations and parkinsonism. Trends Mol Med 17:485-493 
108. Alvarez-Erviti L, Rodriguez-Oroz MC, Cooper JM et al (2010) Chaperone-mediated autophagy markers in Parkinson disease brains. Arch Neurol 67:1464-1472

109. Crews L, Spencer B, Desplats P et al (2010) Selective molecular alterations in the autophagy pathway in patients with Lewy body disease and in models of alpha-synucleinopathy. PLoS One 5:e9313

110. Chu Y, Dodiya H, Aebischer P et al (2009) Alterations in lysosomal and proteasomal markers in Parkinson's disease: relationship to alpha-synuclein inclusions. Neurobiol Dis 35:385-398. doi:10.1016/j.nbd.2009.05.023

111. Xu M, Zhang H (2011) Death and survival of neuronal and astrocytic cells in ischemic brain injury: a role of autophagy. Acta Pharmacol Sin 32:1089-1099

112. Chu CT (2006) Autophagic stress in neuronal injury and disease. J Neuropathol Exp Neurol 65:423-432

113. Schapira AHV (2012) Targeting mitochondria for neuroprotection in Parkinson's disease. Antioxid Redox Signal 16:965-973. doi:10.1089/ars.2011.4419

114. Nixon RA, Yang D-S (2011) Autophagy failure in Alzheimer's disease-locating the primary defect. Neurobiol Dis 43:38-45. doi:10.1016/j.nbd.2011.01.021

115. Pickford F, Masliah E, Britschgi M et al (2008) The autophagyrelated protein beclin 1 shows reduced expression in early Alzheimer disease and regulates amyloid beta accumulation in mice. J Clin Investig 118:2190-2199

116. Yang D-S, Stavrides P, Mohan PS et al (2011) Therapeutic effects of remediating autophagy failure in a mouse model of Alzheimer disease by enhancing lysosomal proteolysis. Autophagy 7:788789

117. Komatsu M, Waguri S, Chiba T et al (2006) Loss of autophagy in the central nervous system causes neurodegeneration in mice. Nature 441:880-884. doi:10.1038/nature04723

118. Hara T, Nakamura K, Matsui M et al (2006) Suppression of basal autophagy in neural cells causes neurodegenerative disease in mice. Nature 441:885-889. doi:10.1038/nature04724

119. Breydo L, Wu JW, Uversky VN (2012) $\alpha$-Synuclein misfolding and Parkinson's disease. Biochim Biophys Acta 1822:261-285. doi:10.1016/j.bbadis.2011.10.002

120. Ullman O, Fisher CK, Stultz CM (2011) Explaining the structural plasticity of $\alpha$-synuclein. J Am Chem Soc 133:19536-19546

121. Wang W, Perovic I, Chittuluru J et al (2011) A soluble $\alpha$-synuclein construct forms a dynamic tetramer. PNAS 108:17797-17802

122. Bartels T, Choi JG, Selkoe DJ (2011) $\alpha$-Synuclein occurs physiologically as a helically folded tetramer that resists aggregation. Nature 3-7. doi: 10.1038/nature10324

123. Lee S-J, Lim H-S, Masliah E, Lee H-J (2011) Protein aggregate spreading in neurodegenerative diseases: Problems and perspectives. Neurosci Res 70:339-348

124. Yonetani M, Nonaka T, Masuda M et al (2009) Conversion of wildtype alpha-synuclein into mutant-type fibrils and its propagation in the presence of A30P mutant. J Biol Chem 284:7940-7950

125. Colla E, Jensen PH, Pletnikova O et al (2012) Accumulation of toxic $\alpha$-synuclein oligomer within endoplasmic reticulum occurs in $\alpha$-synucleinopathy in vivo. $\mathrm{J}$ Neurosci $32: 3301-3305$. doi:10.1523/JNEUROSCI.5368-11.2012

126. Chung CY, Koprich JB, Siddiqi H, Isacson O (2009) Dynamic changes in presynaptic and axonal transport proteins combined with striatal neuroinflammation precede dopaminergic neuronal loss in a rat model of AAV alpha-synucleinopathy. J Neurosci 29:3365-3373. doi:10.1523/JNEUROSCI.5427-08.2009

127. Ihara M, Yamasaki N, Hagiwara A et al (2007) Sept4, a component of presynaptic scaffold and Lewy bodies, is required for the suppression of alpha-synuclein neurotoxicity. Neuron 53:519 533. doi:10.1016/j.neuron.2007.01.019

128. Kahle PJ, Neumann M, Ozmen L et al (2000) Subcellular localization of wild-type and Parkinson's disease-associated mutant alpha-synuclein in human and transgenic mouse brain. J Neurosci 20:6365-6373

129. Yavich L, Jäkälä $P$, Tanila $H$ (2006) Abnormal compartmentalization of norepinephrine in mouse dentate gyrus in alpha-synuclein knockout and A30P transgenic mice. J Neurochem 99:724-732. doi:10.1111/j.1471-4159.2006.04098.x

130. Martin LJ, Pan Y, Price AC et al (2006) Parkinson's disease alphasynuclein transgenic mice develop neuronal mitochondrial degeneration and cell death. J Neurosci 26:41-50. doi:10.1523/ JNEUROSCI.4308-05.2006

131. Devi L, Raghavendran V, Prabhu BM et al (2008) Mitochondrial import and accumulation of alpha-synuclein impair complex I in human dopaminergic neuronal cultures and Parkinson disease brain. J Biol Chem 283:9089-9100. doi:10.1074/jbc.M710012200

132. Loeb V, Yakunin E, Saada A, Sharon R (2010) The transgenic overexpression of alpha-synuclein and not its related pathology associates with complex I inhibition. J Biol Chem 285:7334 7343. doi:10.1074/jbc.M109.061051

133. Chinta SJ, Mallajosyula JK, Rane A, Andersen JK (2010) Mitochondrial alpha-synuclein accumulation impairs complex I function in dopaminergic neurons and results in increased mitophagy in vivo. Neurosci Lett 486:235-239. doi:10.1016/j.neulet.2010.09.061

134. Choubey V, Safiulina D, Vaarmann A et al (2011) Mutant A53T alpha-synuclein induces neuronal death by increasing mitochondrial autophagy. J Biol Chem 286:10814-10824. doi:10.1074/ jbc.M110.132514

135. Esposito A, Dohm CP, Kermer P et al (2007) alpha-Synuclein and its disease-related mutants interact differentially with the microtubule protein tau and associate with the actin cytoskeleton. Neurobiol Dis 26:521-531. doi:10.1016/j.nbd.2007.01.014

136. Lee H-J, Shin SY, Choi C et al (2002) Formation and removal of alpha-synuclein aggregates in cells exposed to mitochondrial inhibitors. J Biol Chem 277:5411-5417. doi:10.1074/jbc.M105326200

137. Chen L, Jin J, Davis J et al (2007) Oligomeric $\alpha$-synuclein inhibits tubulin polymerization. Biochem Biophys Res Commun 356: 548-553. doi:10.1016/j.bbrc.2007.02.163

138. Jensen PH (1999) alpha -Synuclein binds to tau and stimulates the protein kinase A-catalyzed tau phosphorylation of serine residues 262 and 356. J Biol Chem 274:25481-25489. doi:10.1074/jbc. 274.36.25481

139. Frasier M, Walzer M, McCarthy L et al (2005) Tau phosphorylation increases in symptomatic mice overexpressing A30P alpha-synuclein. Exp Neurol 192:274-287. doi:10.1016/j.expneurol.2004.07.016

140. Haggerty T, Credle J, Rodriguez O et al (2011) Hyperphosphorylated Tau in an $\alpha$-synuclein-overexpressing transgenic model of Parkinson's disease. Eur J Neurosci 33:1598-1610. doi:10.1111/ j.1460-9568.2011.07660.x

141. Qureshi HY, Paudel HK (2011) Parkinsonian neurotoxin 1methyl-4-phenyl-1,2,3,6-tetrahydropyridine (MPTP) and alphasynuclein mutations promote Tau protein phosphorylation at Ser262 and destabilize microtubule cytoskeleton in vitro. J Biol Chem 286:5055-5068. doi:10.1074/jbc.M110.178905

142. Clinton LK, Blurton-Jones M, Myczek K et al (2010) Synergistic interactions between Abeta, tau, and alpha-synuclein: acceleration of neuropathology and cognitive decline. J Neurosci 30:72817289

143. Giasson BI, Forman MS, Higuchi M et al (2003) Initiation and synergistic fibrillization of tau and alpha-synuclein. Science 300:636-640. doi:10.1126/science.1082324

144. Smith WW, Jiang H, Pei Z et al (2005) Endoplasmic reticulum stress and mitochondrial cell death pathways mediate A53T mutant alpha-synuclein-induced toxicity. Hum Mol Genet 14:38013811. doi:10.1093/hmg/ddi396

145. Colla E, Coune P, Liu Y et al (2012) Endoplasmic reticulum stress is important for the manifestations of $\alpha$-synucleinopathy in vivo. $\mathrm{J}$ Neurosci 32:3306-3320 
146. Cuervo AM, Stefanis L, Fredenburg R et al (2004) Impaired degradation of mutant alpha-synuclein by chaperone-mediated autophagy. Science 305:1292-1295. doi:10.1126/science.1101738

147. Xilouri M, Vogiatzi T, Vekrellis K et al (2009) Abberant alphasynuclein confers toxicity to neurons in part through inhibition of chaperone-mediated autophagy. PLoS One 4:e5515. doi:10.1371/ journal.pone. 0005515

148. Mazzulli JR, Xu Y-H, Sun Y et al (2011) Gaucher disease glucocerebrosidase and $\alpha$-synuclein form a bidirectional pathogenic loop in synucleinopathies. Cell 146:37-52. doi:10.1016/ j.cell.2011.06.001

149. Tanaka Y, Engelender S, Igarashi S et al (2001) Inducible expression of mutant alpha-synuclein decreases proteasome activity and increases sensitivity to mitochondria-dependent apoptosis. Hum Mol Genet 10:919-926. doi:10.1093/hmg/10.9.919

150. Stefanis L, Larsen KE, Rideout HJ et al (2001) Expression of A53T mutant but not wild-type alpha-synuclein in PC12 cells induces alterations of the ubiquitin-dependent degradation system, loss of dopamine release, and autophagic cell death. J Neurosci 21:9549-9560

151. Petrucelli L, O'Farrell C, Lockhart PJ et al (2002) Parkin protects against the toxicity associated with mutant $\alpha$-synuclein proteasome dysfunction selectively affects catecholaminergic neurons. Neuron 36:1007-1019. doi:10.1016/S0896-6273(02)01125-X

152. Lindersson E, Beedholm R, Højrup P et al (2004) Proteasomal inhibition by alpha-synuclein filaments and oligomers. J Biol Chem 279:12924-12934. doi:10.1074/jbc.M306390200

153. Goedert M, Clavaguera F, Tolnay M (2010) The propagation of prion-like protein inclusions in neurodegenerative diseases. Trends Neurosci 33:317-325

154. Kordower JH, Chu Y, Hauser RA et al (2008) Lewy body-like pathology in long-term embryonic nigral transplants in Parkinson's disease. Nature Medicine 14:504-506. doi:10.1038/nm1747

155. Kordower JH, Chu Y, Hauser RA et al (2008) Transplanted dopaminergic neurons develop PD pathologic changes: a second case report. Mov Disord 23:2303-2306

156. Li J-Y, Englund E, Holton JL et al (2008) Lewy bodies in grafted neurons in subjects with Parkinson's disease suggest host-to-graft disease propagation. Nature Medicine 14:501-503. doi:10.1038/ nm1746

157. Desplats P, Lee H-J, Bae E-J et al (2009) Inclusion formation and neuronal cell death through neuron-to-neuron transmission of alphasynuclein. PNAS 106:13010-13015. doi:10.1073/pnas.0903691106

158. Volpicelli-Daley LA, Luk KC, Patel TP et al (2011) Exogenous $\alpha$ synuclein fibrils induce Lewy body pathology leading to synaptic dysfunction and neuron death. Neuron 72:57-71

159. Luk KC, Kehm V, Carroll J et al (2012) Pathological $\alpha$-synuclein transmission initiates Parkinson-like neurodegeneration in nontransgenic mice. Science 338:949-953. doi:10.1126/ science. 1227157

160. Jang A, Lee H-J, Suk J-E et al (2010) Non-classical exocytosis of alpha-synuclein is sensitive to folding states and promoted under stress conditions. J Neurochem 113:1263-1274

161. Lee H-J, Patel S, Lee S-J (2005) Intravesicular localization and exocytosis of alpha-synuclein and its aggregates. J Neurosci 25:6016-6024

162. Luk KC, Song C, O'Brien P et al (2009) Exogenous alphasynuclein fibrils seed the formation of Lewy body-like intracellular inclusions in cultured cells. PNAS 106:20051-20056

163. Mosley RL, Hutter-Saunders JA, Stone DK, Gendelman HE (2012) Inflammation and adaptive immunity in Parkinson's disease. Cold Spring Harbor perspectives in medicine 2:a009381.

164. McGeer PL, Itagaki S, Akiyama H, McGeer EG (1988) Rate of cell death in parkinsonism indicates active neuropathological process. Ann Neurol 24:574-576

165. Brochard V, Combadière B, Prigent A et al (2009) Infiltration of $\mathrm{CD} 4+$ lymphocytes into the brain contributes to neurodegeneration in a mouse model of Parkinson disease. J Clin Investig 119:182192. doi: $10.1172 / J C I 36470$

166. Double KL, Rowe DB, Carew-Jones FM et al (2009) Antimelanin antibodies are increased in sera in Parkinson's disease. Exp Neurol 217:297-301. doi:10.1016/j.expneurol.2009.03.002

167. Reynolds AD, Stone DK, Hutter J a L et al (2010) Regulatory T cells attenuate Th17 cell-mediated nigrostriatal dopaminergic neurodegeneration in a model of Parkinson's disease. J Immunol 184:2261-2271. doi:10.4049/jimmunol.0901852, Baltimore, Md: 1950

168. Lucin KM, Wyss-Coray T (2009) Immune activation in brain aging and neurodegeneration: too much or too little? Neuron 64:110-122

169. Glass CK, Saijo K, Winner B et al (2010) Mechanisms underlying inflammation in neurodegeneration. Cell 140:918-934. doi:10.1016/ j.cell.2010.02.016

170. Rocha SM, Cristovão AC, Campos FL et al (2012) Astrocytederived GDNF is a potent inhibitor of microglial activation. Neurobiol Dis 47:407-415. doi:10.1016/j.nbd.2012.04.014

171. Nimmerjahn A, Kirchhoff F, Helmchen F (2005) Resting microglial cells are highly dynamic surveillants of brain parenchyma in vivo. Science 308:1314-1318

172. Davalos D, Grutzendler J, Yang G et al (2005) ATP mediates rapid microglial response to local brain injury in vivo. Nat Neurosci 8:752-758

173. Mott RT, Ait-Ghezala G, Town T et al (2004) Neuronal expression of CD22: novel mechanism for inhibiting microglial proinflammatory cytokine production. Glia 46:369-379

174. Majed HH, Chandran S, Niclou SP et al (2006) A novel role for Sema3A in neuroprotection from injury mediated by activated microglia. J Neurosci 26:1730-1738

175. Tian L, Rauvala H, Gahmberg CG (2009) Neuronal regulation of immune responses in the central nervous system. Trends Immunol 30:91-99

176. Koning N, Bö L, Hoek RM, Huitinga I (2007) Downregulation of macrophage inhibitory molecules in multiple sclerosis lesions. Ann Neurol 62:504-514

177. Cardona AE, Pioro EP, Sasse ME et al (2006) Control of microglial neurotoxicity by the fractalkine receptor. Nat Neurosci 9:917-924

178. Kim WG, Mohney RP, Wilson B et al (2000) Regional difference in susceptibility to lipopolysaccharide-induced neurotoxicity in the rat brain: role of microglia. J Neurosci: Off J Soc Neurosci 20: 6309-6316

179. Mena M a, Yébenes $\mathrm{G}$ d J (2008) Immune activation in brain aging and neurodegeneration: too much or too little? Neuroscientist 14:544-560. doi:10.1177/1073858408322839

180. Zecca L, Wilms H, Geick S et al (2008) Human neuromelanin induces neuroinflammation and neurodegeneration in the rat substantia nigra: implications for Parkinson's disease. Acta Neuropathol 116:47-55. doi:10.1007/s00401-008-0361-7

181. McGeer PL, Itagaki S, Boyes BE, McGeer EG (1988) Reactive microglia are positive for HLA-DR in the substantia nigra of Parkinson's and Alzheimer's disease brains. Neurology 38:12851285

182. Langston JW, Forno LS, Tetrud J et al (1999) Evidence of active nerve cell degeneration in the substantia nigra of humans years after 1-methyl-4-phenyl-1,2,3,6-tetrahydropyridine exposure. Ann Neurol 46:598-605

183. McGeer PL, Schwab C, Parent A, Doudet D (2003) Presence of reactive microglia in monkey substantia nigra years after 1methyl-4-phenyl-1,2,3,6-tetrahydropyridine administration. Ann Neurol 54:599-604. doi:10.1002/ana.10728

184. Czlonkowska A, Kohutnicka M, Kurkowska-Jastrzebska I, Czlonkowski A (1996) Microglial reaction in MPTP (1-methyl4-phenyl-1,2,3,6-tetrahydropyridine) induced Parkinson's disease mice model. Neurodegeneration 5:137-143 
185. Walsh S, Finn DP, Dowd E (2011) Time-course of nigrostriatal neurodegeneration and neuroinflammation in the 6hydroxydopamine-induced axonal and terminal lesion models of Parkinson's disease in the rat. Neuroscience 175:251-261. doi:10.1016/j.neuroscience.2010.12.005

186. Gao H, Liu B, Zhang W, Hong J (2003) Critical role of microglial NADPH oxidase-derived free radicals in the in vitro MPTP model of Parkinson's disease. FASEB J 17:1954-1956. doi:10.1096/ fj.03-0109fje

187. Zhang W, Wang T, Pei Z et al (2005) Aggregated alpha-synuclein activates microglia: a process leading to disease progression in Parkinson's disease. FASEB J 19:533-542. doi:10.1096/fj.04$2751 \mathrm{com}$

188. Béraud D, Twomey M, Bloom B et al (2011) $\alpha$-Synuclein alters Toll-like receptor expression. Frontiers in. Neuroscience 5:80

189. Zhang W, Dallas S, Zhang D et al (2007) Microglial PHOX and Mac-1 are essential to the enhanced dopaminergic neurodegeneration elicited by A30P and A53T mutant alpha-synuclein. Glia 55:1178-1188

190. Alvarez-Erviti L, Couch Y, Richardson J et al (2011) Alphasynuclein release by neurons activates the inflammatory response in a microglial cell line. Neurosci Res 69:337-342. doi:10.1016/ j.neures.2010.12.020

191. Gillardon F, Schmid R, Draheim H (2012) Parkinson's diseaselinked leucine-rich repeat kinase $2(\mathrm{R} 1441 \mathrm{G})$ mutation increases proinflammatory cytokine release from activated primary microglial cells and resultant neurotoxicity. Neuroscience 208:41-48. doi:10.1016/j.neuroscience.2012.02.001

192. Frank-Cannon TC, Tran T, Ruhn K a et al (2008) Parkin deficiency increases vulnerability to inflammation-related nigral degeneration. $\mathrm{J}$ Neurosci 28:10825-10834. doi:10.1523/JNEUROSCI.3001-08.2008

193. Waak J, Weber SS, Waldenmaier A et al (2009) Regulation of astrocyte inflammatory responses by the Parkinson's diseaseassociated gene DJ-1. FASEB J 23:2478-2489. doi:10.1096/ fj. $08-125153$

194. Wu DC, Jackson-Lewis V, Vila M et al (2002) Blockade of microglial activation is neuroprotective in the 1-methyl-4-phenyl-1,2,3,6-tetrahydropyridine mouse model of Parkinson disease. J Neurosci 22:1763-1771

195. Perier C, Bové J, Vila M (2012) Mitochondria and programmed cell death in Parkinson's disease: apoptosis and beyond. Antioxid Redox Signal 16:883-895. doi:10.1089/ars.2011.4074

196. Youle RJ, Strasser A (2008) The BCL-2 protein family: opposing activities that mediate cell death. Nat Rev Mol Cell Biol 9:47-59. doi: $10.1038 / \mathrm{nrm} 2308$

197. Tait SWG, Green DR (2010) Mitochondria and cell death: outer membrane permeabilization and beyond. Nat Rev Mol Cell Biol 11:621-632. doi:10.1038/nrm2952

198. Offen D, Beart PM, Cheung NS et al (1998) Transgenic mice expressing human Bcl-2 in their neurons are resistant to 6-hydroxydopamine and 1-methyl-4-phenyl-1,2,3,6- tetrahydropyridine neurotoxicity. PNAS 95:5789-5794

199. Yang L, Matthews RT, Schulz JB et al (1998) 1-Methyl-4-phenyl$1,2,3,6$-tetrahydropyride neurotoxicity is attenuated in mice overexpressing Bcl-2. J Neurosci 18:8145-8152

200. Vila M, Jackson-Lewis V, Vukosavic S et al (2001) Bax ablation prevents dopaminergic neurodegeneration in the 1-methyl- 4phenyl-1,2,3,6-tetrahydropyridine mouse model of Parkinson's disease. PNAS 98:2837-2842. doi:10.1073/pnas.051633998

201. Perier C, Bové J, Wu D-C et al (2007) Two molecular pathways initiate mitochondria-dependent dopaminergic neurodegeneration in experimental Parkinson's disease. PNAS 104:8161-8166. doi:10.1073/pnas.0609874104

202. Dietz GPH, Stockhausen KV, Dietz B et al (2008) Membranepermeable Bcl-xL prevents MPTP-induced dopaminergic neuronal loss in the substantia nigra. J Neurochem 104:757-765. doi:10.1111/j.1471-4159.2007.05028.x
203. Iaccarino C, Crosio C, Vitale C et al (2007) Apoptotic mechanisms in mutant LRRK2-mediated cell death. Hum Mol Genet 16:1319-1326. doi:10.1093/hmg/ddm080

204. Darios F, Corti O, Lücking CB et al (2003) Parkin prevents mitochondrial swelling and cytochrome $c$ release in mitochondriadependent cell death. Hum Mol Genet 12:517-526

205. Petit A, Kawarai T, Paitel E et al (2005) Wild-type PINK1 prevents basal and induced neuronal apoptosis, a protective effect abrogated by Parkinson disease-related mutations. J Biol Chem 280:34025-34032. doi:10.1074/jbc.M505143200

206. Wang H-L, Chou A-H, Yeh T-H et al (2007) PINK1 mutants associated with recessive Parkinson's disease are defective in inhibiting mitochondrial release of cytochrome $c$. Neurobiol Dis 28:216-226. doi:10.1016/j.nbd.2007.07.010

207. Boya P, Kroemer G (2008) Lysosomal membrane permeabilization in cell death. Oncogene 27:6434-6451. doi:10.1038/onc.2008.310

208. Turk B, Turk DSA, Turk V (2012) Protease signalling: the cutting edge. EMBO J 31:1630-1643. doi:10.1038/emboj.2012.42

209. Jeon S-M, Cheon S-M, Bae H-R et al (2010) Selective susceptibility of human dopaminergic neural stem cells to dopamineinduced apoptosis. Exp Neurobiol 19:155-164. doi:10.5607/ en.2010.19.3.155

210. Benner EJ, Banerjee R, Reynolds AD et al (2008) Nitrated alphasynuclein immunity accelerates degeneration of nigral dopaminergic neurons. PLoS One 3:e1376. doi:10.1371/journal.pone.0001376

211. Gao H-M, Zhou H, Zhang F et al (2011) HMGB1 acts on microglia Mac1 to mediate chronic neuroinflammation that drives progressive neurodegeneration. J Neurosci 31:1081-1092. doi:10.1523/ JNEUROSCI.3732-10.2011

212. Simi A, Tsakiri N, Wang P, Rothwell NJ (2007) Interleukin-1 and inflammatory neurodegeneration. Biochem Soc Trans 35:1122-1126

213. McCoy MK, Tansey MG (2008) TNF signaling inhibition in the CNS: implications for normal brain function and neurodegenerative disease. J Neuroinflammation 5:45. doi:10.1186/1742-2094$5-45$

214. Magrane M, Consortium U (2011) UniProt Knowledgebase: a hub of integrated protein data. Database (Oxford) 2011:bar009.

215. Seal RL, Gordon SM, Lush MJ et al (2011) genenames.org: the HGNC resources in 2011. Nucleic Acids Res 39:D514-D519

216. Cochrane G, Akhtar R, Bonfield J et al (2009) Petabyte-scale innovations at the European Nucleotide Archive. Nucleic Acids Res 37:19-25

217. Flicek P, Amode MR, Barrell D et al (2012) Ensembl 2012. Nucleic Acids Res 40:84-90

218. Fujita PA, Rhead B, Zweig AS et al (2011) The UCSC Genome Browser database: update 2011. Nucleic Acids Res 39:D876D882

219. Pruitt KD, Tatusova T, Brown GR, Maglott DR (2012) NCBI Reference Sequences (RefSeq): current status, new features and genome annotation policy. Nucleic Acids Res 40:D130-D135

220. Maglott D, Ostell J, Pruitt KD, Tatusova T (2011) Entrez Gene: gene-centered information at NCBI. Nucleic Acids Res 39:D52D57

221. Schuler GD (1997) Pieces of the puzzle: expressed sequence tags and the catalog of human genes. J Mol Med 75:694-698

222. Safran M, Dalah I, Alexander J, et al. (2010) Gene Cards Version 3: the human gene integrator. Database (Oxford) 2010:baq020.

223. Berman H, Henrick K, Nakamura H, Markley JL (2007) The worldwide Protein Data Bank (wwPDB): ensuring a single, uniform archive of PDB data. Nucleic Acids Res 35:D301-D303

224. Ashburner M, Ball CA, Blake JA et al (2000) Gene ontology: tool for the unification of biology. The Gene Ontology Consortium. Nat Genet 25:25-29

225. Kanehisa M, Goto S, Sato Y et al (2012) KEGG for integration and interpretation of large-scale molecular data sets. Nucleic Acids Res 40:D109-D114 
226. Mi H, Lazareva-Ulitsky B, Loo R et al (2005) The PANTHER database of protein families, subfamilies, functions and pathways. Nucleic Acids Res 33:D284-D288

227. Croft D, O'Kelly G, Wu G et al (2011) Reactome: a database of reactions, pathways and biological processes. Nucleic Acids Res 39:D691-D697

228. Punta M, Coggill PC, Eberhardt RY et al (2012) The Pfam protein families database. Nucleic Acids Res 40:290-301

229. Hunter S, Jones P, Mitchell A et al (2012) InterPro in 2011: new developments in the family and domain prediction database. Nucleic Acids Res 40:D306-D312

230. cDonagh EM, Whirl-Carrillo M, Garten Y et al (2011) From pharmacogenomic knowledge acquisition to clinical applications: the PharmGKB as a clinical pharmacogenomic biomarker resource. Biomark Med 5:795-806

231. Zhang Y, James M, Middleton FA, Davis RL (2005) Transcriptional analysis of multiple brain regions in Parkinson's disease supports the involvement of specific protein processing, energy metabolism, and signaling pathways, and suggests novel disease mechanisms. Am J Med Genet 137B:5-16. doi:10.1002/ ajmg.b.30195

232. Lesnick TG, Papapetropoulos S, Mash DC et al (2007) A genomic pathway approach to a complex disease: axon guidance and Parkinson disease. PLoS Genet 3:12

233. Moran LB, Duke DC, Deprez M et al (2006) Whole genome expression profiling of the medial and lateral substantia nigra in Parkinson's disease. Neurogenetics 7:1-11

234. Zheng B, Liao Z, Locascio JJ et al (2010) PGC-1 $\alpha$, a potential therapeutic target for early intervention in Parkinson's disease. Sci Transl Med 2:52ra-73ra

235. Scherzer CR, Eklund AC, Morse LJ et al (2007) Molecular markers of early Parkinson's disease based on gene expression in blood. PNAS 104:955-960

236. Sforza D, Hartenstein P, Lacan G, et al. (2008) Gene expression changes in multiple brain regions of a mouse MPTP model of Parkinson's disease. Fairfax, VA 22030 USA

237. Foti R, Zucchelli S, Biagioli M et al (2010) Parkinson diseaseassociated DJ-1 is required for the expression of the glial cell linederived neurotrophic factor receptor RET in human neuroblastoma cells. J Biol Chem 285:18565-18574

238. Rajagopalan D, Agarwal P (2005) Inferring pathways from gene lists using a literature-derived network of biological relationships. Bioinformatics 21:788-793. doi:10.1093/bioinformatics/bti069

239. Ulitsky I, Shamir R (2009) Identifying functional modules using expression profiles and confidence-scored protein interactions. Bioinformatics 25:1158-1164. doi:10.1093/bioinformatics/btp118

240. Cerami E, Demir E, Schultz N et al (2010) Automated network analysis identifies core pathways in glioblastoma. PLoS One 5: e8918. doi:10.1371/journal.pone.0008918

241. Tusher VG, Tibshirani R, Chu G (2001) Significance analysis of microarrays applied to the ionizing radiation response. PNAS 98:5116-5121. doi:10.1073/pnas.091062498

242. Aerts S, Lambrechts D, Maity S et al (2006) Gene prioritization through genomic data fusion. Nat Biotechnol 24:537-544. doi: $10.1038 /$ nbt 1203

243. Ma X, Lee H, Wang L, Sun F (2007) CGI: a new approach for prioritizing genes by combining gene expression and protein-protein interaction data. Bioinformatics 23:215-221. doi:10.1093/ bioinformatics/bt1569

244. Zaykin DV, Zhivotovsky LA, Czika W et al (2007) Combining $p$ values in large-scale genomics experiments. Pharm Stat 6:217226. doi:10.1002/pst.304

245. Marot G, Foulley J-L, Mayer C-D, Jaffrézic F (2009) Moderated effect size and $P$-value combinations for microarray metaanalyses. Bioinformatics 25:2692-2699
246. Aittokallio T, Schwikowski B (2006) Graph-based methods for analysing networks in cell biology. Brief Bioinform 7:243-255. doi:10.1093/bib/bbl022

247. Emmert-Streib F, Dehmer M (2011) Networks for systems biology: conceptual connection of data and function. IET Syst Biol 5:185. doi:10.1049/iet-syb.2010.0025

248. Junker BH, Schreiber F (2008) Analysis of biological networks. Science 1-28. doi:10.1002/9780470253489

249. Guimerà R, Sales-Pardo M, Amaral LAN (2007) Classes of complex networks defined by role-to-role connectivity profiles. Nat Phys 3:63-69. doi:10.1038/nphys489

250. Wang R-S, Albert R (2011) Elementary signaling modes predict the essentiality of signal transduction network components. BMC Syst Biol 5:44

251. Klipp E, Liebermeister W (2006) Mathematical modeling of intracellular signaling pathways. BMC Neurosci 7(Suppl 1):S10. doi:10.1186/1471-2202-7-S1-S10

252. Hucka M, Finney a, Sauro HM (2003) The systems biology markup language (SBML): a medium for representation and exchange of biochemical network models. Bioinformatics 19:524 531. doi:10.1093/bioinformatics/btg015

253. Hoops S, Sahle S, Gauges R et al (2006) COPASI-a COmplex PAthway SImulator. Bioinform (Oxford, England) 22:3067-3074. doi:10.1093/bioinformatics/btl485

254. Van Eunen K, Kiewiet J a L, Westerhoff HV, Bakker BM (2012) Testing biochemistry revisited: how in vivo metabolism can be understood from in vitro enzyme kinetics. PLoS Comput Biol 8: e1002483. doi:10.1371/journal.pcbi.1002483

255. Kowald A, Hamann A, Zintel S et al (2012) A systems biological analysis links ROS metabolism to mitochondrial protein quality control. MechAgeing Dev 133:331-337. doi:10.1016/j.mad.2012. 03.008

256. Berndt N, Bulik S, Holzhütter H-G (2012) Kinetic modeling of the mitochondrial energy metabolism of neuronal cells: the impact of reduced $\alpha$-ketoglutarate dehydrogenase activities on ATP production and generation of reactive oxygen species. International journal of cell biology 2012:757594. doi: 10.1155/2012/757594

257. Craddock TJ a, Tuszynski J a, Chopra D et al (2012) The zinc dyshomeostasis hypothesis of Alzheimer's disease. PLoS One 7: e33552. doi:10.1371/journal.pone. 0033552

258. Ambert N, Greget R, Haeberlé O et al (2010) Computational studies of NMDA receptors: differential effects of neuronal activity on efficacy of competitive and non-competitive antagonists. Open Access Bioinforma 2:113-125. doi:10.2147/OAB.S7246

259. Berardini TZ, Li D, Muller R, et al. (2012) Assessment of community-submitted ontology annotations from a novel database-journal partnership. Database : the journal of biological databases and curation 2012:bas030. doi: 10.1093/database/bas030

260. Meyer P, Alexopoulos LG, Bonk T et al (2011) Verification of systems biology research in the age of collaborative competition. Nat Biotechnol 29:811-815. doi:10.1038/nbt.1968

261. Meyer P, Hoeng J, Rice JJ et al (2012) Industrial methodology for process verification in research (IMPROVER): toward systems biology verification. Bioinform (Oxford, England) 28:11931201. doi:10.1093/bioinformatics/bts 116

262. Nielsen MA (2011) Reinventing discovery: the new era of networked science. Princeton University Press, Princeton, NJ

263. Kelder T, Van Iersel MP, Hanspers K et al (2012) WikiPathways: building research communities on biological pathways. Nucleic Acids Res 40:D1301-D1307. doi:10.1093/nar/gkr1074

264. Matsuoka Y, Ghosh S, Kikuchi N, Kitano H (2010) Payao: a community platform for SBML pathway model curation. Bioinformatics 26:1381-1383. doi:10.1093/bioinformatics/btq143

265. Le Novère N, Hucka M, Mi H et al (2009) The systems biology graphical notation. Nat Biotechnol 27:735-741 